\title{
Bombay blood phenotype: Laboratory detection and transfusions recommendations
}

\author{
Nicholas Suraci, Maximo Mora
}

\begin{abstract}
Four main blood types routinely identified today are $A, B, A B$, and $O$. Universal donors have type "O" blood, and have no "A" or "B" antigens. In turn, no blood reactions will occur in recipients. Conversely, universal recipients having type "AB" blood will have no antibodies to the "A" or " $B$ " antigens. Bombay phenotype has no " $A$ " or " $B$ " antigens, classifying it as " $O$ " blood type. Furthermore, Bombay phenotype lacks expression of the $H$ antigen, which is present on every blood cell. When mixed with any type of blood other than Bombay blood, hemolytic reactions occur. A 55-year-old male had his blood typed and screened after trauma activation for an eye injury. On forward grouping, the patient was identified as blood type " $O$ ". On reverse grouping, agglutination occurred. Laboratory procedures were evaluated and an expanded antigen panel was performed which confirmed this agglutination, which led to the suspicion of a rare blood type. The patient did not require blood transfusion and was further evaluated by New York Blood Center where the diagnosis of Bombay Phenotype was confirmed. This case emphasizes the importance of proper laboratory investigations for rare blood types, preventative strategies, as well as management of Bombay blood type.
\end{abstract}

Nicholas Suraci ${ }^{1}$, Maximo Mora ${ }^{2}$

Affiliations: ${ }^{* * * *}$

Corresponding Author: Nicholas Paul Suraci, PO box 457, Mifflinville, PA, USA, 18631; Email: Nicholas.suraci@gmail. com

Received: 31 December 2015

Accepted: 11 February 2016

Published: 29 March 2016
Keywords: Antigen, Bombay, Blood, Group

\section{How to cite this article}

SuraciN,MoraM.Bombayblood phenotype:Laboratory detection and transfusions recommendations. Int $\mathrm{J}$ Blood Transfus Immunohematol 2016;6:8-11.

Article ID: 100023IJBTINS2016

$* * * * * * * * *$

doi:10.5348/ijbti-2016-23-CR-3

\section{INTRODUCTION}

There are four main blood types identified: $A, B, A B$, and O. If a person has type "A" blood, this refers to them having an "A" antigen on the red blood cell. Subsequently, the patient with this type will have antibodies to type "B". Those with type "O" blood type have no antigens present, but have antibodies to both " $\mathrm{A}$ " and " $\mathrm{B}$ " antigens. This is why type "O" blood is referred to as the universal donor. Conversely, those with $\mathrm{AB}$ blood types have no antibodies and are thus deemed universal recipients of blood (Figure 1).

Bombay phenotype was first discovered in Bombay, India in 1952. In this blood group, no "A" or "B" antigens are identified on red blood cells or in secretions. By definition, that would fit type "O" blood type. In Bombay phenotype, there is a void of A antigen, B Antigen as well as $\mathrm{H}$ antigen [1]. It is presumed that the $\mathrm{H}$ antigen is a precursor carbohydrate from which A and B blood groups are formed. All blood cells, except for Bombay, express the $\mathrm{H}$ antigen. People having this blood type are mostly confined to Southeast Asia. About 1/10, o00 of the 
population in that region have Bombay blood group. A high level of consanguinity presents among the parents of the Bombay phenotype. Caucasian incidence is $1 / 250$, 000 $[2,3]$.

When Bombay blood group is misdiagnosed, fatal hemolytic transfusion reactions occur. For this reason, and because of its rarity, inaccurate interpretation has led to these adverse effects [2].

\section{CASE REPORT}

A 55-year-old male originating from India was brought in for trauma activation for a right eye injury and severe weight loss. Blood was drawn for type and screen. When the forward test was performed, the patient was found to have neither blood type A nor type B antigens on red blood cells, as there were no reaction to Anti-A and Anti-B reagent antibodies. Therefore, he was considered type $\mathrm{O}$ blood type (Table 1). Reverse grouping was performed to identify the patient's serum antibodies. Results showed agglutination with type A and B red cells, as well as the "O" blood type. In a 2-cell antibody screen, the patient's serum demonstrated antibodies, as evidenced by agglutination of both cells. As per blood bank laboratory policy, an expanded antigen panel was then performed. Results showed pan-agglutination. Cold agglutinins were suspected which prompted the laboratory to perform a DAT. Results of the DAT were negative. At this point, it raised attention because some other antigen not on the panel was responsible for this finding. Now, the presence of a rare blood type was also suspected. After repeating the tests and determining it was not a laboratory procedure error, further evaluation was required. The patient did not require blood transfusion; however, the reference laboratory of New York Blood Center was contacted and blood samples were sent to identify the correct blood type. It was at their facility that it was found that the patient had the rare Bombay phenotype.

At the New York Blood Center the patient's blood was forward grouped and reverse grouped, as done in Jamaica Hospital. Reverse grouping demonstrated panagglutination. Cold agglutinins were suspected. DAT was performed and results were negative. An expanded panel, which had anti-H lectin, was then performed on the patient's blood. Normally, all blood types will agglutinate with anti-H lectin. This patient did not react with anti-H lectin, confirming Bombay phenotype. Typing for the $\mathrm{H}$ antigen was negative and its absence was confirmed with genomic DNA analysis. This proved the absence of $\mathrm{H}$-antigen, confirming the Bombay phenotype. H-blood group substance was then added to anti-H serum in vitro and neutralization occurred. This confirmed the presence of anti-H in the serum.

\section{DISCUSSION}

The Bombay phenotype is characterized by the absence of $\mathrm{A}, \mathrm{B}$, and $\mathrm{H}$ antigens on its red cells and the serum of these individuals have anti-A and anti-B [4]. But the serum that agglutinates red cells of ' $\mathrm{O}$ ' group individuals through a wide thermal range may be due to presence of strongly reactive anti-H antibodies [5]. It was identified that the $h$ allele is a result of mutation of the $\mathrm{H}$ gene (FUTI) that would express the $\mathrm{H}$ antigen on the red blood cell of ABO blood groups. Bombay phenotype is homozygous (hh) for the $725 \mathrm{G}$ mutation in the FUT1 coding region; the consequence of this mutation is the production of an inactivated enzyme, the enzyme needed in the production of the $\mathrm{H}$ antigen [1]. Furthermore, this $\mathrm{H}$ substance is bio-chemically produced by the binding of Fucose to the surface glycoproteins, the process being catalyzed by fucosyltransferase. Blood group A is formed when $\mathrm{N}$-acetyl-galactosamine binds to the $\mathrm{H}$ substance. If galactose binds to the $\mathrm{H}$ substance, blood group $\mathrm{B}$ is

Table 1: Forward and Reverse Grouping with Blood Groups. (+) =Agglutination, $(-)=$ No reactivity

\begin{tabular}{lcccccc}
$\begin{array}{l}\text { B l o o d } \\
\text { Group }\end{array}$ & \multicolumn{3}{c}{ Forward Group } & \multicolumn{3}{c}{ Reverse Group } \\
\hline & Anti-A & Anti-B & $\begin{array}{c}\text { Anti- } \\
\text { A,B }\end{array}$ & $\begin{array}{c}\text { A1 } \\
\text { Cells }\end{array}$ & $\begin{array}{c}\text { B } \\
\text { Cells }\end{array}$ & $\begin{array}{c}\text { Cells } \\
\text { A }\end{array}$ \\
& + & - & + & - & + & - \\
B & - & + & + & + & - & - \\
AB & + & + & + & - & - & - \\
O & - & - & - & + & + & - \\
Bombay & - & - & - & + & + & + \\
\hline
\end{tabular}
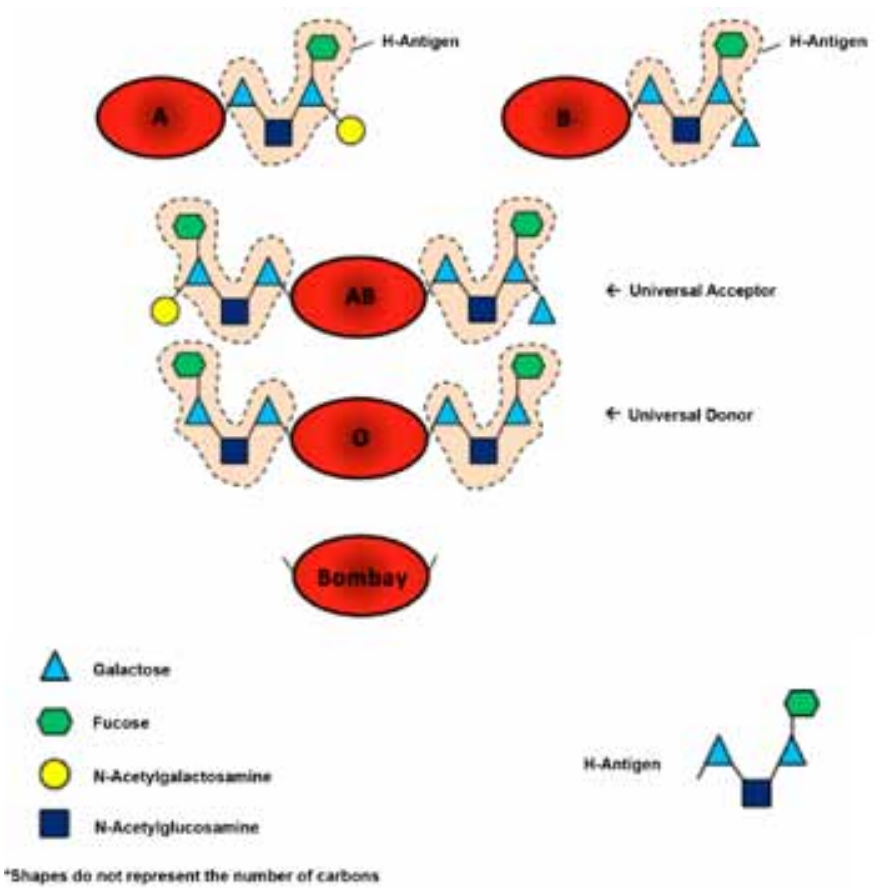

Figure 1: Structural components of blood group phenotype. 
formed. If neither substance binds to $\mathrm{H}$, O blood group is the result [6]. Individuals that fail to express $\mathrm{H}$ transferase (FUT1) lack the $\mathrm{H}$ antigen, which is the foundation of Bombay phenotype. Individuals that lack this expression cannot synthesize A or B antigenic structures regardless of their $\mathrm{ABO}$ blood given genotype, and $\mathrm{ABH}$ antigens are absent from both their erythrocytes and secretions [7].

The practice of tribal and territorial endogamy is small population leads to smaller gene pools. Consequently, increased expression of homozygous genetic characters like Bombay phenotype occurs. One study further validates this in areas of India where consanguinity is commonly practiced [4].

During cell grouping or forward grouping, Bombay blood group would be categorized as $\mathrm{O}$ group because it would not show any reaction to anti-A and anti-B antibodies just like a normal $\mathrm{O}$ group would do. When a cross matching with different blood bags of $\mathrm{O}$ group is done, then it would show cross-reactivity or incompatibility [6]. This is a flag and should be the point where more thorough evaluation is needed. Therefore, reverse grouping or serum grouping has to be performed to suspect the Bombay blood group. It has been suggested to incorporate "routine serum typing or reverse grouping confirmation" along with "O" cell control in reverse grouping procedure in every transfusion medicine department, blood bank or blood donor centers and that this practice should be mandatory to reduce the risk of fatal hemolytic transfusion reactions [2].

The concern with Bombay blood group is that the individuals having this group can only receive either autologous blood donation or blood from an individual of Bombay phenotype [4]. It is important to identify it in emergent situations, because any other type of blood being used can have lethal effects on the recipient. It is recommended that individuals with Bombay blood group should get all their family members and relatives tested for the blood group. They should also register themselves with leading blood banks so that in case of emergency they can be contacted [4]. In other suggestions, cryopreservation facilities for rare donor units have been recommended. If the blood banks can borrow or exchange rare blood units in times of need, a lot of problems related to rare blood groups like the Bombay blood group can be solved. This is only possible if each blood bank has a large number of committed regular voluntary donors [6]. In the absence of blood donor registry, transfusion management of patients needing immediate surgery can be challenging [8]. Acute normovolemic hemodilution (ANH) is a blood conservation technique that entails the removal of blood from a patient shortly after induction of anesthesia, with maintenance of normovolemia using crystalloid and/or colloid replacement. The blood is infused into the patient during or shortly after the surgical procedure [9]. ANH is available, cost effective for suitable patients and reduces blood viscosity [8]. Newer research with stem cells has provided an opportunity to produce a universal blood group donor, in vitro, thus enabling cellular replacement therapies, once the safety issue is resolved [10].

For this patient, blood transfusion was not required. However, the patient did not meet the standards for an autologous blood donation. An alert medical bracelet was given to the patient to show identification of his condition.

\section{CONCLUSION}

In conclusion, this is a notable case because it emphasizes the importance of proper laboratory investigation for any suspicion of rare blood types as well as identification and management of the Bombay phenotype.

\section{$* * * * * * * * *$}

\section{Acknowledgements \\ Clinical Investigators}

1. Vivian Martinez: Served as scientific investigator

2. Elmer Ariza: Served as scientific investigator

3. Svetlana Nuridzhanyants: Served as scientific investigator

\section{Participating Investigator}

1. John Flynt: Critically reviewed the report and contributed to figure and table design

\section{Author Contributions}

Nicholas Paul Suraci - Substantial contributions to conception and design, Acquisition of data, Analysis and interpretation of data, Drafting the article, Revising it critically for important intellectual content, Final approval of the version to be published

Maximo Mora - Substantial contributions to conception and design, Revising it critically for important intellectual content, Final approval of the version to be published

\section{Guarantor}

The corresponding author is the guarantor of submission.

\section{Conflict of Interest}

Authors declare no conflict of interest.

\section{Copyright}

(C) 2016 Nicholas Paul Suraci et al. This article is distributed under the terms of Creative Commons Attribution License which permits unrestricted use, distribution and reproduction in any medium provided the original author(s) and original publisher are properly credited. Please see the copyright policy on the journal website for more information.

\section{REFERENCES}

1. Das S, Kumar HRA. Bombay Blood A Rare Entity. Journal of Clinical Biomedical Science 2011;1(3):1225 . 
2. Dipta TF, Hossain AZ. The Bombay blood group: are we out of risk? Mymensingh Med J 2011 Jul;20(3):536-40.

3. Dipta TFA, Hossain KN, Khatun A, et al. Bombay Phenotype: Report of 2 Cases. Journal of Bangladesh College of Physicians and Surgeons 2011;29(4):2413 .

4. Balgir RS. Identification of a rare blood group, "Bombay (Oh) phenotype," in Bhuyan tribe of Northwestern Orissa, India. Indian J Hum Genet 2007 Sep;13(3):109-13.

5. Malhotra S, Dhawan HK, Jain A, Sachdev S, Marwaha N. Acute Hemolytic Transfusion Reaction in a Patient with Bombay Phenotype: Implications for $\mathrm{ABO}$ Grouping. Indian J Hematol Blood Transfus 2014 Sep;30(Suppl 1):108-10.

6. Khan M. Bombay Blood Group: A Case Report. The Pacific Journal of Science and Technology 2009 May;10(1):333-7.

7. O'Donnell JS, McKinnon TA, Crawley JT, Lane DA, Laffan MA. Bombay phenotype is associated with reduced plasma-VWF levels and an increased susceptibility to ADAMTS13 proteolysis. Blood 2005 Sep 15;106(6):1988-91.

8. Shrivastava M, Navaid S, Peethambarakshan A, Agrawal K, Khan A. Detection of rare blood group, Bombay (Oh) phenotype patients and management by acute normovolemic hemodilution. Asian J Transfus Sci 2015 Jan-Jun;9(1):74-7.

9. Avidan M, Silvergleid A. Surgical blood conservation: Intraoperative hemodilution. In: Kleinman $\mathrm{S}$, Hines $\mathrm{R}$ eds. UpToDate, Waltham, MA. [Available at: http://www.uptodate.com/contents/surgical-bloodconservation-intraoperative-hemodilution]

10. Seifinejad A, Taei A, Totonchi M, et al. Generation of human induced pluripotent stem cells from a Bombay individual: moving towards "universal-donor" red blood cells. Biochem Biophys Res Commun 2010 Jan 1;391(1):329-34.
Access full text article on other devices

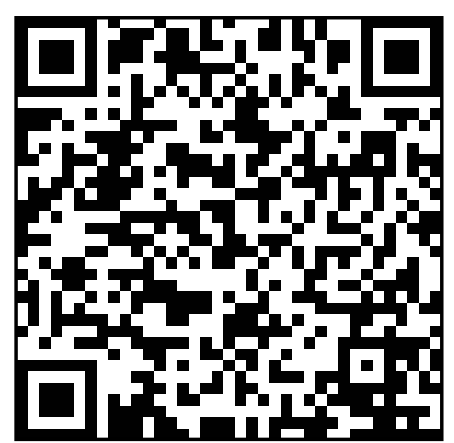

Access PDF of article on other devices

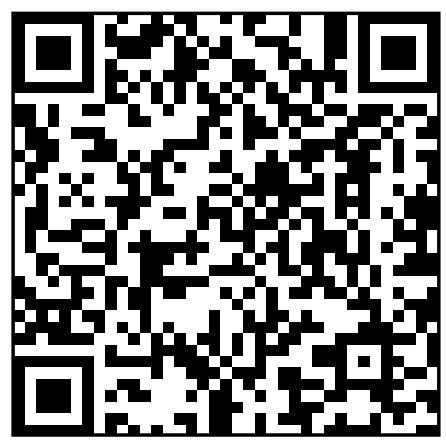

